\title{
Linearization of High frequency Class E Feedback Amplifier using Negative Impedance Method
}

\author{
MD. Shoaib Sikder and M. Tanseer Ali, Dept of Electrical and Electronics Engineering, American \\ International University-Bangladesh, Dhaka, Bangladesh
}

\begin{abstract}
This work represents a novel method of linearization of Switch Mode Power Amplifier (SMPA). For this purpose, class E SMPA was designed and analyzed both before and after applying a linearization technique known as the Negative Impedance method. One of the major characteristics of a standard SMPA is that they have higher efficiency than their linear counterpart but on the other hand they show highly nonlinear characteristics. The motivation behind this work is to harness this highly efficient amplifier and make it linear which can be very useful for various applications in RF communication fields. All the schematics and simulations that are presented in this paper were performed using the Cadence Virtuoso environment using the "Spectre" simulator tool. For active components, $280 \mathrm{~nm}$ process technology was used under "gpdk90" pdk which is based on BSIM3v3 model. The gpdk90 package includes devices ranging from $100 \mathrm{~nm}$ to $280 \mathrm{~nm}$ processes for different voltage levels. The $280 \mathrm{~nm}$ process was chosen as it supports a maximum of $2.5 \mathrm{~V}$ of supply. The Circuit was designed to run at $2 \mathrm{GHz}$ with $2.5 \mathrm{~V}$ supply voltage. A mathematical model is also presented using data found from the analysis, with the help of MATLAB. Linearity was measured using Input referred Intercept Point of $3^{\text {rd }}$ order frequency (IIP3), which was improved from $3.7 \mathrm{dBm}$ to $17.86 \mathrm{dBm}$ with $57 \%$ percent efficiency providing an output power of $15.78 \mathrm{dBm}$.
\end{abstract}

Index Terms-SMPA, Class E amplifier, Linearity, IIP3, PAE, Schmitt Trigger

\section{INTRODUCTION}

A present, the $4^{\text {th }}$ industrial revolution is becoming more $\mathbf{1}_{\text {and more apparent. The }} 4^{\text {th }}$ industrial revolution enables all the modern technology used in every sphere to combine into a single entity where the technologies can communicate to

This paper was submitted to AIUB Journal of Science and Engineering (AJSE) on May $4^{\text {th }}, 2021$. Special thanks to AJSE committee for accepting this work and for adding value to this work by giving constructive reviews.

M.S. Sikder, is a student of Masters program in Electrical and Electronics Engineering at American International University-Bangladesh, Dhaka, Bangladesh (email: shoaibsikder2013@gmail.com)

M. T. Ali is the Senior Assistant Professor, Special Assistant [EEE] of Computer Engineering Department, American International UniversityBangladesh, Dhaka, Bangladesh (email: tanseer@aiub.edu) each other for better functioning of the device itself as well as for the whole system. Thus, machine-to-machine wireless communication will be on the rise. So, it is crucial to develop circuit designs to improve wireless RF communication. One of the most used circuits in the RF field is a power amplifier (PA). One can find at least one PA in every transmitter or receiver block in the communication system. They are also used in repeaters to increase the signal strength in long transmission mediums. There are two basic types of PA, one the linear PA other one is Switch Mode PA. The basic difference between them is that linear PA has active devices working in the saturation region, unlike SMPA where the active device works only as a switch. This makes the SMPA advantageous over its linear counterpart in terms of efficiency but SMPA suffers from nonlinear behavior. Hence special care needs to be taken to improve linearity. There are many linearization techniques available. The most prominent ones are feedback, feedforward, cross cancellation, Analog predistortion, digital pre-distortion, negative impedance method, etc. In this work, a Class E SMPA was designed running at $2 \mathrm{GHz}$ with $2.5 \mathrm{~V}$ supply and analyzed utilizing the negative impedance method, which is an extended version of the previous work cited in [5]. The contribution of this work is the concept of applying the negative impedance method in switchmode power amplifiers such as Class E amplifiers and analyze their behavior. The simulation analysis was done both before and after applying the linearization technique. All the simulation was done using Cadence Virtuoso utilizing "Spectre" simulator tool. Later on, a mathematical model was introduced which is generated from Spectre and modeled using MATLAB. The active device for this work is from "gpdk90" Process Design Kit (PDK) consisting MOSFETs in $280 \mathrm{~nm}$ process technology. The gpdk90 package includes devices ranging from $100 \mathrm{~nm}$ to $280 \mathrm{~nm}$ processes for different voltage levels. The $280 \mathrm{~nm}$ process was chosen as it supports a maximum of $2.5 \mathrm{~V}$ of supply. 


\section{EARLIER RESEARCH}

One of the earliest researches on class E SMPA was carried out by N.O.Sokal et al [1] back in 1970 where a basic understanding of SMPA was presented mentioning design methodologies and compared different types of PAs. The following table shows a comparison of PA in terms of max power delivered and maximum frequency.

TABLE I Comparison among different types of PA

\begin{tabular}{|c|c|c|c|}
\hline Class & $\operatorname{Pmax}(W)$ & Efficiency (\%) & Comments \\
\hline $\mathrm{A}$ & 0.125 & 50 & $\begin{array}{l}360^{\circ} \text { conduction } \\
\text { angle }\end{array}$ \\
\hline $\mathrm{B}$ & 0.125 & 78.5 & $\begin{array}{l}180^{\circ} \text { conduction } \\
\text { angle }\end{array}$ \\
\hline \multirow[t]{2}{*}{$\mathrm{C}$} & 0.0981 & 89.6 & $\begin{array}{l}120.6^{\circ} \text { conduction } \\
\text { angle }\end{array}$ \\
\hline & 0 & 100 & $0^{\circ}$ conduction angle \\
\hline $\mathrm{D}$ & 0.318 & 100 & Uses two devices \\
\hline E & 0.0981 & 100 & $\begin{array}{l}\text { Optimum } 50 \% \text { duty } \\
\text { cycle }\end{array}$ \\
\hline $\mathrm{F}$ & 0.159 & 100 & $\begin{array}{l}\text { Infinite number of } \\
\text { resonators }\end{array}$ \\
\hline $\mathrm{S}$ & 0.125 & 100 & AC coupled \\
\hline
\end{tabular}

The values that are presented in table 1 are found from [1] and all the values are taken considering ideal conditions. A more intuitive as well as calculative approach was given in a book in [2] by Hella et al. where a class E amplifier is designed for personal area networks. Functional block diagram for class E SMPA can be found in both [1] and [2], where the SMPA is divided into three blocks namely, the driver stage, the active switch, and the load network. On the other hand, a slightly different approach was taken by R.Kubowicz in [3], where a class E amplifier was imagined as an RLC tank circuit. According N.O.Sokal and Hella et al., the driver stage must produce square pulses of $50 \%$ duty cycle to provide an equal amount of time to charge and discharge the energy stored in the inductor and capacitor of the resonator. On the other hand, A. Mediano et al in [4] presented a circuit design of a class $\mathrm{E}$ amplifier that can operate at any duty cycle with the help of very large shunt capacitance across the switch. Again, a unique approach was shown in [5] by M.S. Sikder where a Schmitt trigger is utilized to make $50 \%$ duty cycle square pulses to drive a class $\mathrm{E}$ amplifier making the design cost-effective in terms of low area. Among the earliest research on linearization technique feedforward technique is a prominent one done by Bennett et al in [6]. A bit more advanced designs were described by T. Rahkonen et al in [7] where an analog polynomial pre-distortion circuit utilizing the gilbert cell to reduce the spectral widening. Furthermore, Chi - Tsan Chen et al in [8] described an approach involving a digital envelop predistorter to linearize a class $\mathrm{E}$ power amplifier. Moreover, P Sampath et al in [9], designed an analog pre-distortion with the help of the square law method. In this work, another modern approach was utilized which known negative impedance method developed by M.T.Ali et al shown from [10] to [12] where an adjustment current is introduced at the input side of a differential amplifier which helps to increase its linearity. The novelty of this work is the application of this method on a highly nonlinear class E switch-mode power amplifier and observe its linearity as well as other performance parameters. All the simulation results that are shown in this paper are done in the cadence virtuoso environment using "Spectre" simulator [13]. The active devices are 280nm CMOS process of "gpdk90" pdk using "BSIM3v3" device model [14]. In the end, a class E amplifier was achieved running at $2 \mathrm{GHz}$ delivering $15.78 \mathrm{dBm}$ of power at the output with IIP3 of $17.86 \mathrm{dBm}$

\section{SCHEMATIC DESIGN}

\section{A. Design Conditions}

In [1] and [2] the authors have clearly described design methodology and key concepts for SMPA, especially on Class E Power Amplifier. Some of the important considerations and conditions are shown below,

- At the moment of turning on, there should be no voltage drop across the active switch and the voltage slope should be zero as well.

- The output of the driver should produce square wave pulses of $50 \%$ duty cycle.

- There is a tradeoff for increased device sizes and turn-on resistance. With increased width, the onresistance will drop but it will increase its parasitic capacitance which impacts the resonant frequency.

\section{B. Circuit Description}

R.Kubowicz has shown his work given in [2] describing the Class E Amplifier as RLC parallel circuit. The designed functional circuit using ideal components is represented in figure 1.

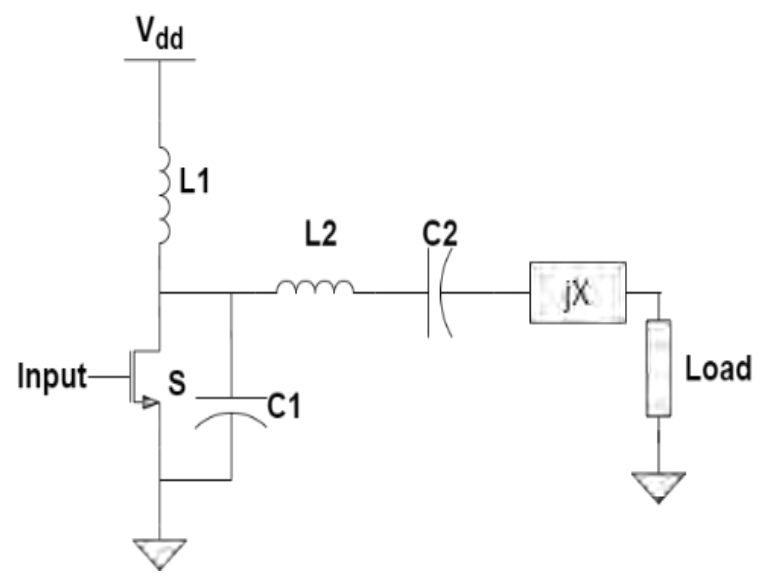

Fig. 1. Functional schematic of class E amplifier [3]

In the figure, it is depicted that the device $\mathrm{S}$ is a MOSFET acting as a switch with choke inductance L1, and $\mathrm{C} 1$ is the shunt capacitance connected at the drain terminal. The input of the switch comes from the driver stage. The inductor-capacitor series circuit shown as L2 and C2 acts as a series resonant circuit with a resonant frequency of $2 \mathrm{GHz}$. The inductance $\mathrm{jX}$ 
shown in the figure fixes the phases of voltage and current at the output delivering power to the load. The values of the passive elements are shown in the following table.

TABLE II Values of the passive components

\begin{tabular}{|l|l|}
\hline Components & Values \\
\hline Choke inductor, L1 & $5 \mathrm{nH}$ \\
\hline Phase correction inductor, $\mathrm{jX}$ & $500 \mathrm{pH}$ \\
\hline Shunt capacitor, C1 & $500 \mathrm{fF}$ \\
\hline Series resonance capacitor, C2 & $672.17 \mathrm{fF}$ \\
\hline Series resonance inductor, L2 & $2.18 \mathrm{nH}$ \\
\hline
\end{tabular}

\section{Driver Circuit design}

In this work, the driver stage was chosen to a Schmitt trigger type for which the design is found from [5] by M.S. Sikder. The design of the driver stage is shown in figure 2.

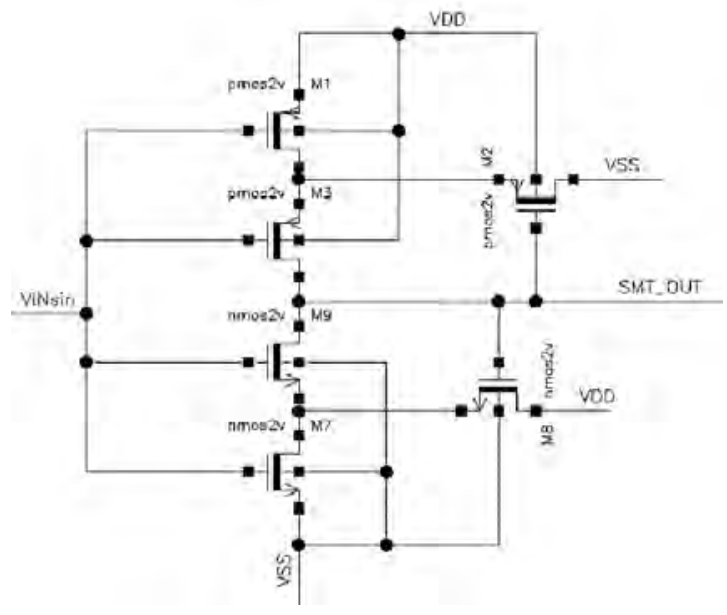

Fig. 2. Schmitt Trigger Schematic.

According to C.Zhang in [15], the Schmitt trigger gives more noise immunity as well as control over the switching threshold by adding hysteresis.

\section{Impedance Matching Network}

The load matching or impedance matching network is used to deliver maximum available power to the load. The impedance of the ports is taken to be 50ohms standard load according to [16]. Both input and output impedance was measured in simulation by pumping $1 \mathrm{~A}$ of current at each designated net and measured the voltage on that net. The input and output impedance was found to be $325 \mathrm{ohms}$ and $80 \mathrm{ohms}$. The matching networks for both input and output are shown in figure 3 .

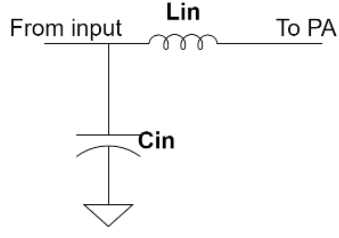

(a)

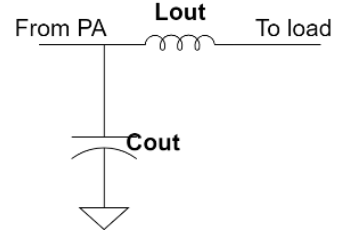

(b)
Fig. 3. Impedance matching network (a) input side (b) output side
The values of the inductor and capacitor for the matching network are found from the equations found in [17] and shown below.

For matching network at the input side shown in figure 3(a)

$$
\begin{aligned}
& \left.Q=\sqrt{\left(\frac{R L}{R S}\right.}-1\right) \\
& \operatorname{Cin}=\frac{Q}{\omega R L} \\
& \operatorname{Lin}=\frac{1}{\omega^{2} \times C 1}\left(\frac{Q^{2}}{Q^{2}+1}\right)
\end{aligned}
$$

For matching network at the output side shown in figure 3(a)

$$
\begin{aligned}
& \left.Q=\sqrt{\left(\frac{R L}{R S}\right.}-1\right) \\
& \text { Cout }=\frac{Q R S}{\omega} \\
& \text { Lout }=\frac{1}{\omega^{2} \times C 2}\left(\frac{Q^{2}}{Q^{2}+1}\right)
\end{aligned}
$$

Here in equations (1), (2), and (3), RL and RS stand for the input resistance of the amplifier along with the driver and input port resistance respectively. On the other hand, in equation (4), (5) and (6), RL and RS is the port impedance and amplifier output impedance. Moreover, Cin and Lin are the inductor and capacitor for the input side matching network and Cout and Lout are for the output side matching network respectively. After some further tuning, the following values were found which are shown in Table II.

TABLE II Matching network element values

\begin{tabular}{|l|l|l|}
\hline Elements & Name & Value \\
\hline Inductor & Lin & $21.72 \mathrm{nH}$ \\
\cline { 2 - 3 } & Lout & $2.18 \mathrm{nH}$ \\
\hline Capacitor & Cin & $282 \mathrm{fF}$ \\
\cline { 2 - 3 } & Cout & $672.17 \mathrm{fF}$ \\
\hline
\end{tabular}

\section{E. Circuit Operation}

The basic understanding of the class E amplifier can be found in [1] and [2], where it has been divided into three functional parts. The block diagram in figure 4 shows their functional behavior.

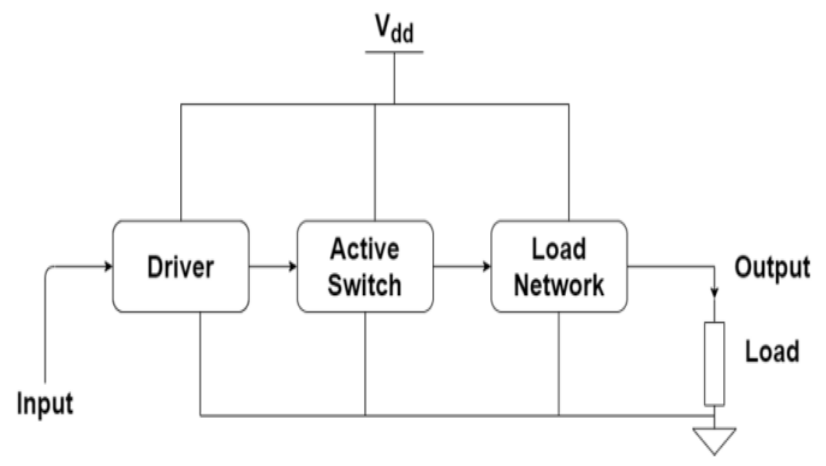

Fig. 4. conceptual block diagram class E switch-mode power amplifier. 
The circuit operations can be described as RLC resonant circuit according to R Kubowicz in [3]. The equivalent circuit is presented below in fig 5 .

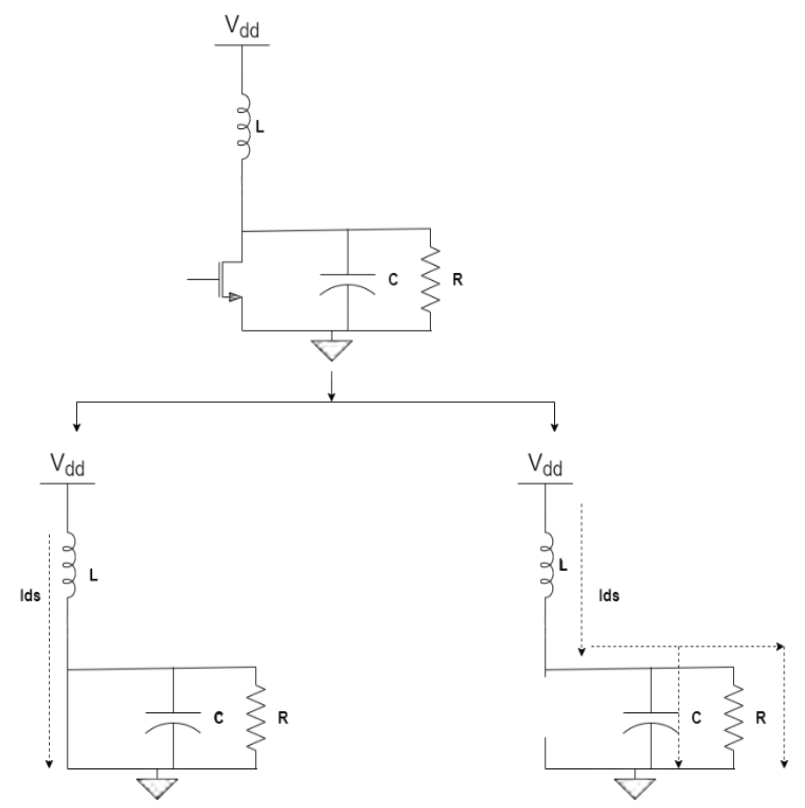

Fig. 5. Equivalent circuit of class E amplifier [2]

When the active switch turns on the current flows through choke inductance L, and when the switch is turned off the current flows through the shunt capacitance and load resistance denoted as $\mathrm{C}$ and $\mathrm{R}$ respectively in figure 5. The circuit works as RLC parallel resonant circuit when the switch is open with a resonant frequency given as

$$
f=\frac{1}{2 \pi \sqrt{L C}}
$$

The switching frequency has to be similar to the resonant frequency to ensure proper charge and discharge of energy between the inductor and capacitor. A duty cycle of $50 \%$ is also required to ensure no overlap between drain voltage and current. The ideal waveform of drain voltage and current is shown in figure 6.

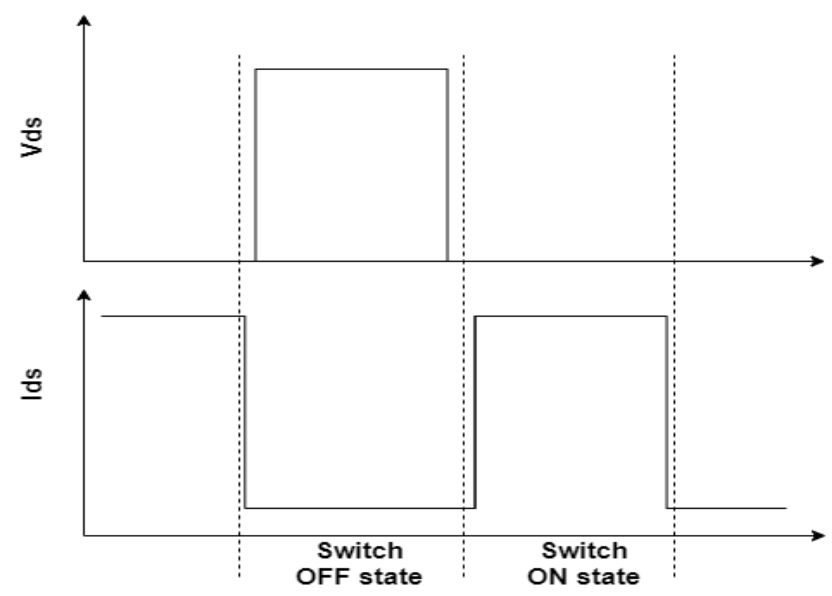

Fig. 6. Drain voltage and current waveform across an ideal switch of Class E SMPA[1]
Moreover, a series resonant circuit with a resonant frequency equal to the input frequency is placed before the load resistance as in fig 1, to get a sinusoidal waveform at the output.

\section{F. Negative Impedance Method}

The negative impedance method for linearization of amplifiers was first described by R.Wu et al in [16]. Later on, M.T. Ali et al in [10] modeled his negative feedback amplifier with negative impedance linearization using the Volterra series. Again, in [12] R. Wu describes the linearization scheme using the close loop differential amplifier shown below in fig 6 .

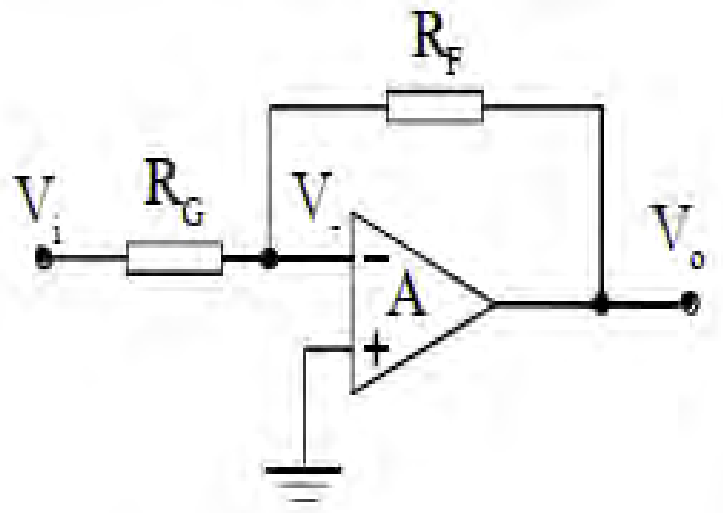

Fig. 7. Negative feedback differential amplifier [12]

The gain equation for figure 10 can be written as

$$
-\frac{V 0}{R F}=\frac{V i n}{R G}
$$

Equation 8 is only valid in ideal cases. Hence considering nonlinearities, equation 8 can be rewritten as according to [12],

$$
-\frac{V 0}{R F}-\frac{V 0}{A}\left(\frac{1}{Z i}+\frac{1}{R F}+\frac{1}{R G}\right)=\frac{V i n}{R G}
$$

From the left-hand side of equation (9), the second term is denoted as distortion current, id [12].

$$
i d=-\frac{V_{0}}{A}\left(\frac{1}{\mathrm{Zi}}+\frac{1}{R F}+\frac{1}{R G}\right)
$$

This distortion component, id can be addressed using the negative impedance method which generates anti-distortion current, iad. Figure 8 shows the implementation of this method which can be found in [12].

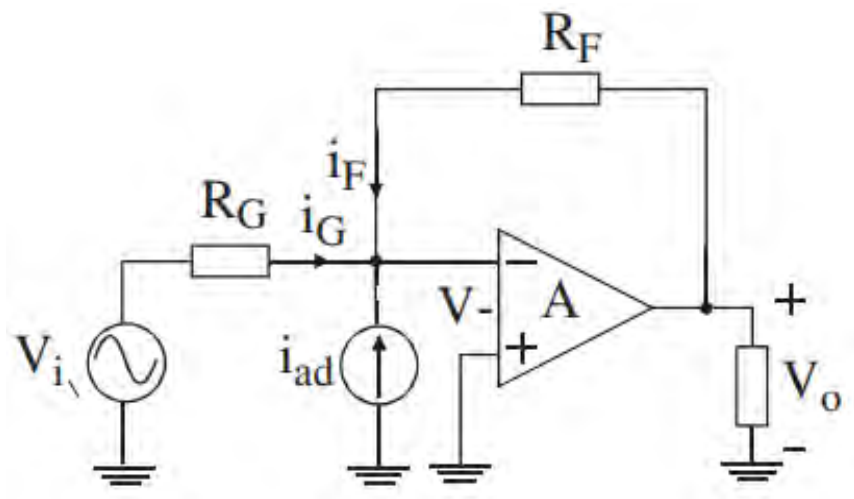

Fig. 8. Conceptual implementation of negative impedance method [12] 
According to $\mathrm{R} . \mathrm{Wu}$ in [12], if this anti-distortion current is made equal to the distortion current non-linearities should cancel out.

From fig 11 , by applying KCL at the input node, the antidistortion current stands as,

$$
\text { iad }=i i-i G-i F
$$

Hence, by measuring the current from the input source, $\mathrm{iG}$, feedback current, iF, and the current through the inverting input terminal ii, the anti-distortion current can be found out.

\section{SimUlation RESULTS AND ANALYSIS}

\section{A. Performed Simulations}

In this section, the results of the performed simulations are analyzed both before and after applying the linearization method. The performed simulations are DC analysis, Transient analysis, and Periodic Steady-state analysis. Later on, a mathematical model is also presented which was done with the help of MATLAB.

\section{B. Assumptions}

As in design, a number of considerations and assumptions were taken into account before going into the details of simulation results. The design considerations are stated below.

- Passive components that are used are considered to be ideal

- The design is tested for only a sinusoidal wave input with $1.4 \mathrm{~V}$ swing and $1.24 \mathrm{~V} \mathrm{DC}$ offset running at $2 \mathrm{GHz}$

- The results that are presented are all pre-layout simulation

- The condition of the simulation was in typical process corner at $27^{\circ} \mathrm{C}$ temperature with a nominal supply voltage of $2.5 \mathrm{~V}$

\section{Simulations on the Driver stage}

At first DC simulation was performed to find out the amount of hysteresis was added to the design. The resultant hysteresis curve is shown in figure 9.

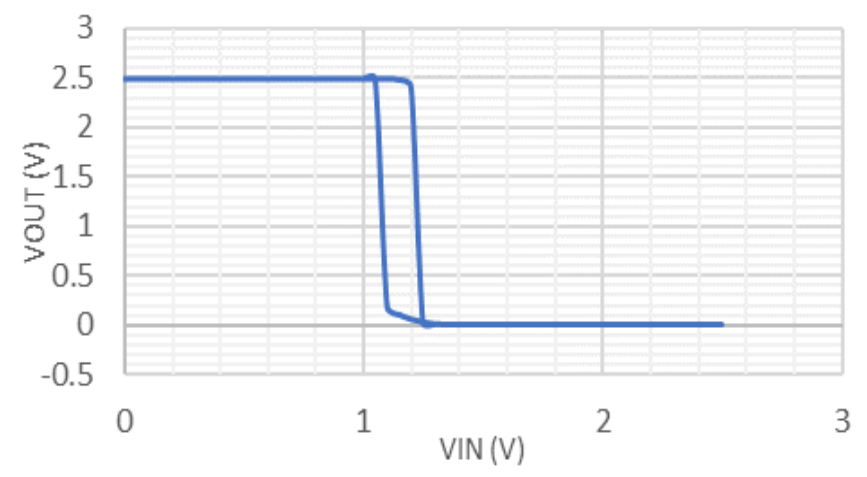

Fig.9. Hysteresis of Schmitt trigger

The curve in Figure 9 shows the output hysteresis when the input is swept from 0 to supply voltage, VDD. The RF signal that is coming from the input side is prone to noise. Having a hysteresis provides different tripping points which help to remove unwanted switching at the output of the driver and eliminating noise that would go into the power stage of the designed amplifier.

\section{Testbench}

A conceptual diagram of the class $\mathrm{E}$ amplifier testbench without linearization is presented in figure 10 .

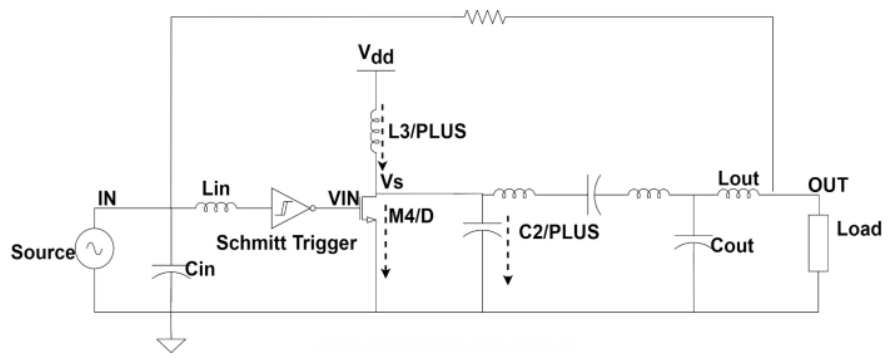

Fig. 10. Conceptual diagram of the simulated testbench

In figure 10, the source and load impedance were $50 \mathrm{ohms}$, and the feedback resistance was chosen to be $200 \mathrm{k}$. The performed simulations on this testbench are transient analysis and PSS analysis.

\section{E. Transient Analysis}

In order to observe the output waveforms at various nodes transient analysis was performed. The resultant waveform is shown below in figure 11.

In figure 11, both external and internal waveforms of voltage and current are presented. The probing points are highlighted in figure 10. From the top, the solid VIN curve shows the square output of the Schmitt trigger driver for the input stated as IN shown in a dashed sinusoidal curve. Next, the curve denoted as L3/PLUS shows the waveform of current through the choke inductor which rises slowly to the peak when the NMOS turns on i.e., VIN is high. Again, M4/D and C2/PLUS waveforms are current waveforms of drain and shunt capacitor respectively. The flow of drain current is high whenever the VIN signal is high and when VIN is low the drain current is reduced and the current starts to flow through the shunt capacitor which is shown in the dashed waveform denoted as C2/PLUS. Moreover, the voltage across the switch or NMOS, denoted as Vs in the waveform, reaches its maximum value only when the VIN signal is low, otherwise, it stays at a minimal magnitude. Thus, by observing the waveform of drain current M4/D and drain voltage Vs, it is found that there is little overlap which is the basic functionality of class $\mathrm{E}$ amplifier. The overlap that is present will contribute to power dissipation.

\section{F. Periodic Steady State Analysis}

The periodic steady state or PSS analysis was performed on the class E amplifier to find output several measurements such as output power, output power gain, and most importantly linearity test from IIP3 curve. This simulation was done using harmonic balance engine with consideration of five harmonics at the output.

The output frequency domain plot of output power and gain is presented below in figure 12 . 


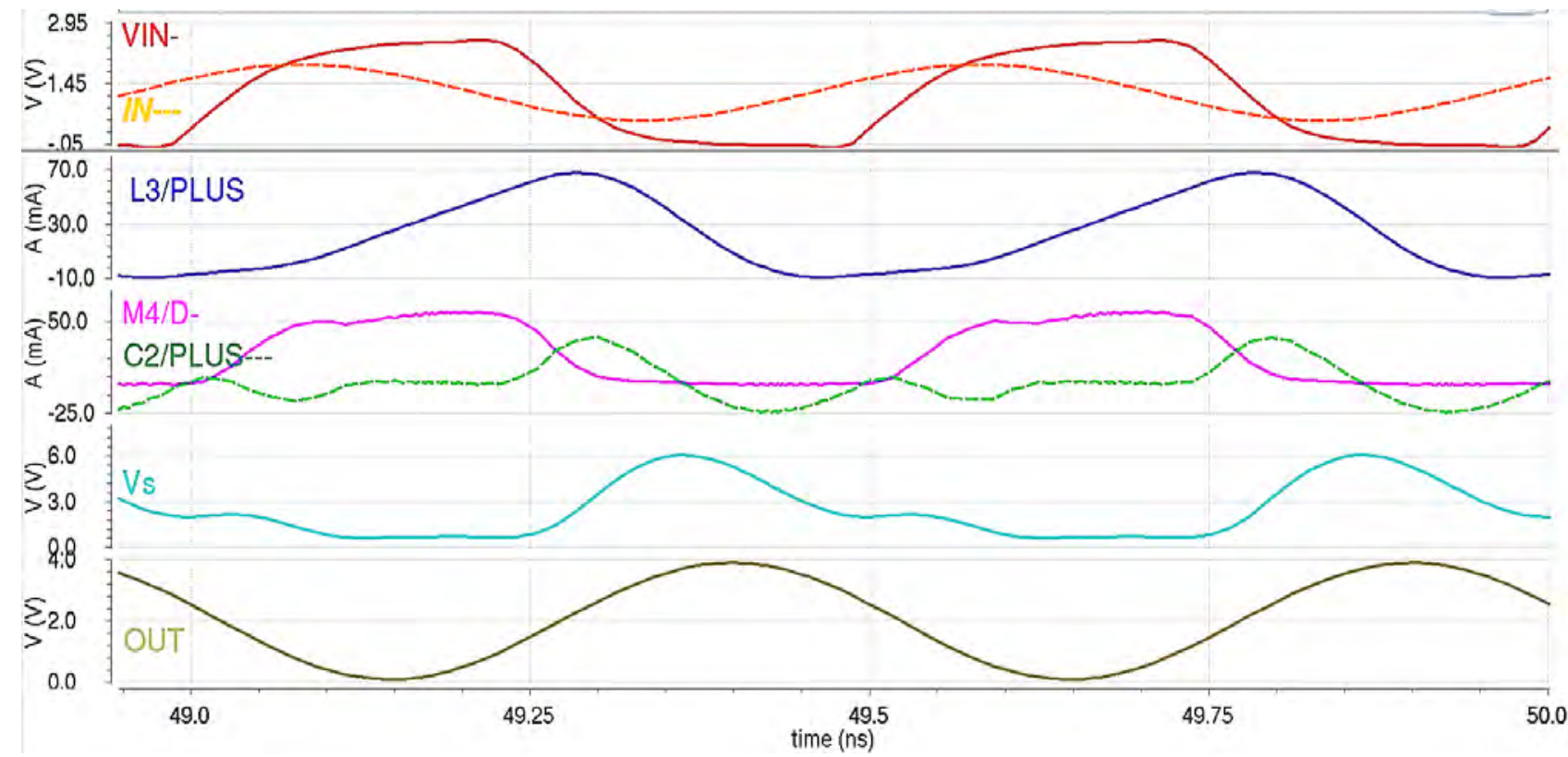

Fig. 11. Transient analysis waveforms of class $\mathrm{E}$ amplifier

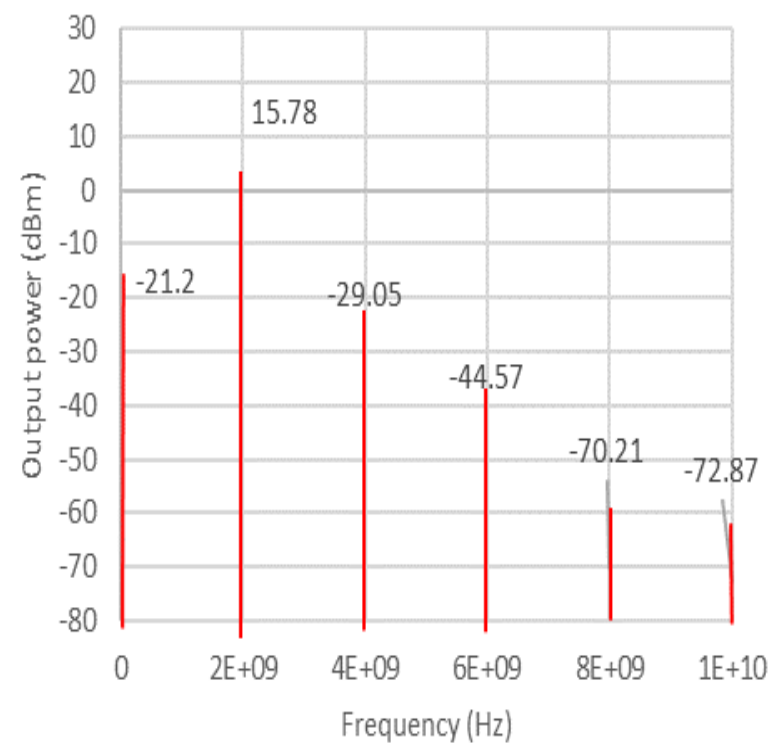

Fig. 12. Output power measurement

The measurement from figure 12 shows that the output power was found to $15.78 \mathrm{dBm}$ at the fundamental component.

The gain in power at the fundamental is shown below in figure 13. The gain was calculated to be $11.41 \mathrm{~dB}$ with respect to an input power of $6 \mathrm{dBm}$.

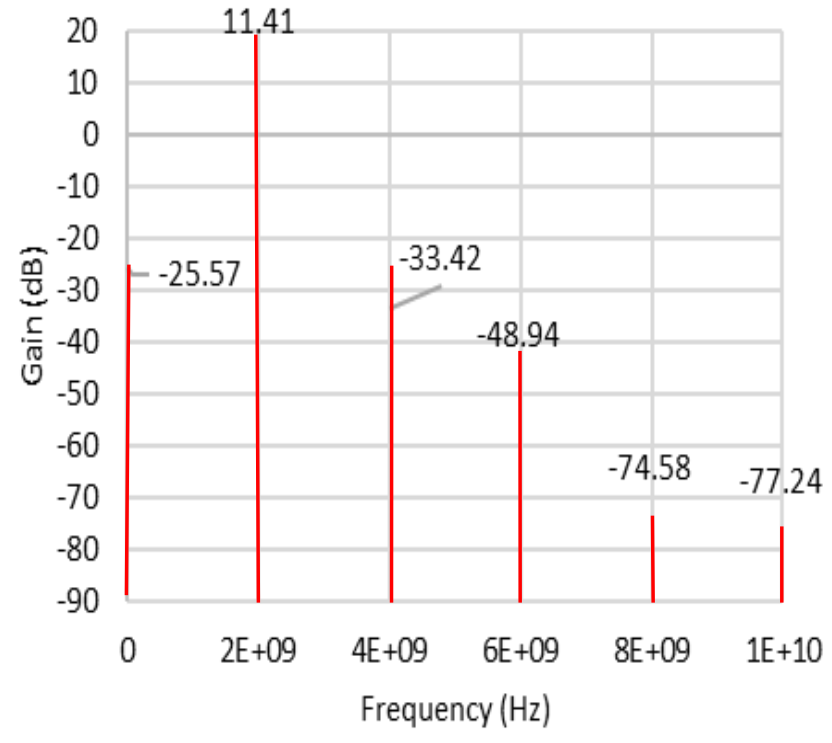

Fig 13. Output power gain in dB10

Moreover, during the PSS analysis power added efficiency was also measured and the simulated results are presented below in figure 14 . 


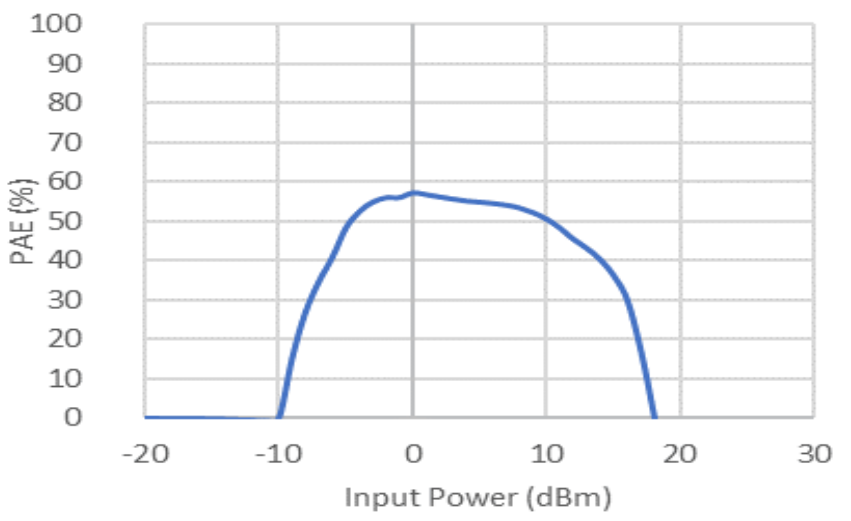

Fig. 14. Power added efficiency plot with respect to input power

The PAE plot shown in figure 14 was measured by sweeping the input power from $-20 \mathrm{dBm}$ to $30 \mathrm{dBm}$. The maximum efficiency was found to be around $57 \%$. The main source of power reduction is the overlap drain voltage and current which is observed in transient waveforms shown in figure 11.

\section{G. Linearity test before applying linearization}

As a measure of linearity Input referred Intercept Point of $3^{\text {rd }}$ order frequency (IIP3) curve was chosen as it shows a plot of output power against the input power of both $1^{\text {st }}$ and $3^{\text {rd }}$ order frequencies and their intercepting point of linear approximation curve. The following figure shows the IIP3 curve before applying linearization.

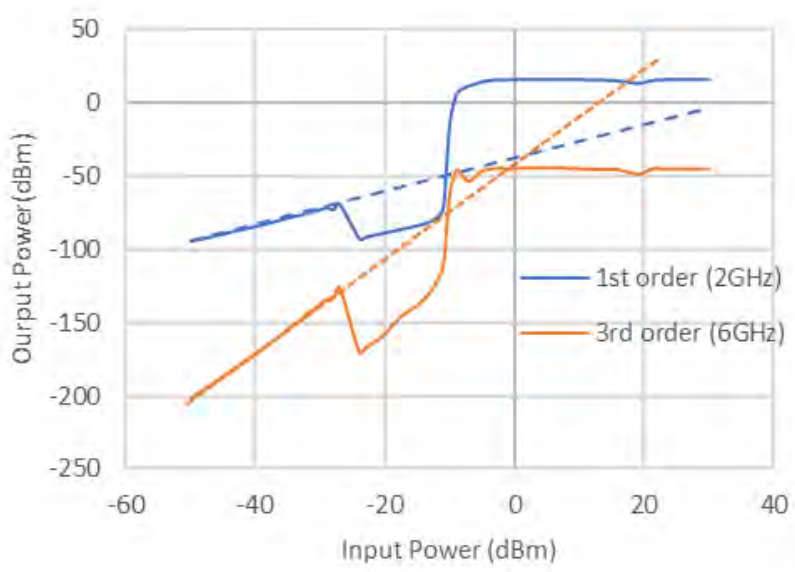

Fig. 15. IIP3 curve before application of linearization

From figure 15 it is seen that; the curve shows nonlinear behavior which is expected for a switch-mode power amplifier. The dashed line is the linear approximation of the curves and they intercept at the input power of $3.7 \mathrm{dBm}$. Hence, the input referred intercept point is $3.7 \mathrm{dBm}$. Moreover, it is also observed that the amplifier does not have any usable gain below $-10 \mathrm{dBm}$ of input power.

\section{H. Implementation of negative impedance}

The negative impedance linearization was implemented on the following testbench shown in figure 16 .
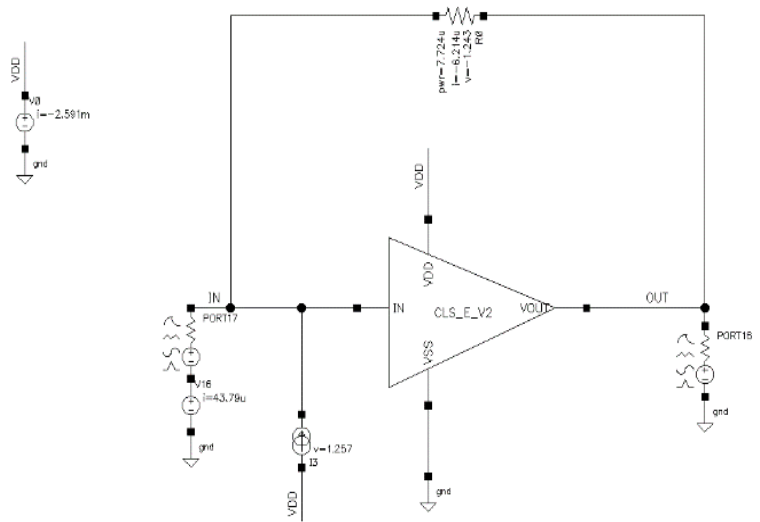

Fig. 16. Test bench of negative impedance linearization

In figure 15, the instance named "CLS_E_V2" is the class E amplifier which has a feedback resistance of $200 \mathrm{~K}$. At the input node, a current source is present which supplies the antidistortion current. The magnitude of this current was estimated according to equation (11). Later on, it was further tuned to get better results. The final value of the current was found to be 40uA. After applying the anti-distortion current, the same simulations as shown previously were performed. Apart from linearity improvement, all the results seem to be the same. The following figure shows the IIP3 curve after applying the linearization scheme.

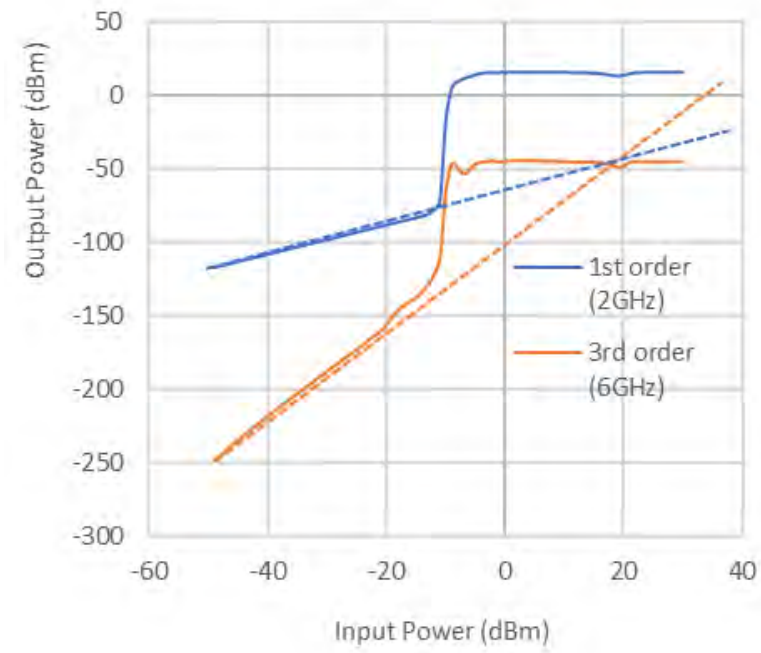

Fig. 17. IIP 3 curve of $1^{\text {st }}$ and $3^{\text {rd }}$ order frequencies after applying linearization

It is observed that in figure 17 the intercepting point is at around $17.86 \mathrm{dBm}$ referred to input which was previously at $3.7 \mathrm{dBm}$. Hence there is an improvement of around $12.08 \mathrm{dBm}$.

\section{Final Specification}

After running the simulations both before and after applying the linearization scheme, it is found that the linearity has improved by $12.08 \mathrm{dBm}$ as seen from the IIP 3 curves from figure 15 and figure 17 . The final achieved specification of the designed amplifier along with linearization is shown in table III. 
TABLE III. specification table

\begin{tabular}{|l|l|}
\hline Specification (unit) & Value \\
\hline Supply voltage $(\mathrm{V})$ & 2.5 \\
\hline Fundamental Frequency $(\mathrm{GHz})$ & 2 \\
\hline Output power at fundamental $(\mathrm{dBm})$ & 15.78 \\
\hline Power gain at fundamental $(\mathrm{dB})$ & 11.41 \\
\hline PAE (\%) & $54-57$ \\
\hline IIP3 before linearization $(\mathrm{dBm})$ & 3.7 \\
\hline IIP3 after linearization $(\mathrm{dBm})$ & 17.86 \\
\hline
\end{tabular}

\section{J. Performance Comparison}

The relevant performance parameters of the designed amplifier were compared against some previous works that are shown in Table VI.

TABLE IV: specification and comparison with previous studies

\begin{tabular}{|l|l|l|l|l|}
\hline Ref & $\begin{array}{l}\text { Transistor } \\
\text { model }\end{array}$ & $\begin{array}{l}\text { Frequency } \\
(\mathbf{G H z})\end{array}$ & $\begin{array}{l}\text { Gain } \\
(\mathbf{d B})\end{array}$ & $\begin{array}{l}\text { PAE } \\
\mathbf{( \% )}\end{array}$ \\
\hline$[20]$ & GaN HEMT & $1.9 \mathrm{GHz}$ & 10 & $57-62$ \\
\hline$[21]$ & GaN HEMT & $2-2.5 \mathrm{GHz}$ & $10-13$ & $71-74$ \\
\hline$[22]$ & GaN HEMT & $0.9-2.2 \mathrm{GHz}$ & $10-13$ & $63-89$ \\
\hline$[23]$ & GaN HEMT & $0.9-2.3 \mathrm{GHz}$ & $7.5-13$ & $57-88$ \\
\hline $\begin{array}{l}\text { This } \\
\text { work }\end{array}$ & BSIM3v3 & $2 \mathrm{GHz}$ & 11.4 & $54-57$ \\
\hline
\end{tabular}

The comparative analysis shows that BSIM3v3 model shows similar performance as GaN HEMT technology in terms of gain and PAE. The only drawback is that BSIM3v3 is lowpower MOSFET. Even so, it may perform well enough for lower power applications.

\section{K. Mathematical Model}

The mathematical model was designed from the data found from the IIP3 curves. The IIP3 curves shown in figure 15 and figure 17 are actually the transfer characteristics of the designed amplifier both before and after applying linearization. Hence, a polynomial equation can be found by curve fitting analysis yielding the desired mathematical model. The curve fitting analysis was done with the help of MATLAB with data found from Cadence Virtuoso. The following figure 18 shows the fitted curve for both $1^{\text {st }}$ and $3^{\text {rd }}$ order frequencies after applying linearization.

From the fitted curves found in figure 18, a polynomial equation can be made. The following table shows the power coefficients up to $7^{\text {th }}$ order of power for both $1^{\text {st }}$ and $3^{\text {rd }}$ order frequencies.
TABLE $V$ power coefficient for $1^{\text {st }}$ and $3^{\text {rd }}$ order frequencies before linearization

\begin{tabular}{|l|l|l|}
\hline Input power order & $\begin{array}{l}\text { Coefficients for } \mathbf{1}^{\text {st }} \\
\text { order frequency } \\
\text { (dBm) }\end{array}$ & $\begin{array}{l}\text { Coefficients for } \mathbf{3}^{\text {rd }} \\
\text { order frequency } \\
(\mathbf{d B m})\end{array}$ \\
\hline Pin $^{0}$ & 14.6591 & -45.9544 \\
\hline Pin & 2.0927 & 2.5196 \\
\hline Pin $^{2}$ & 0.7468 & 0.8828 \\
\hline Pin $^{3}$ & -0.6383 & -0.7653 \\
\hline $\operatorname{Pin}^{4}$ & -0.0887 & -0.0978 \\
\hline $\operatorname{Pin}^{5}$ & 0.0576 & 0.0680 \\
\hline $\operatorname{Pin}^{6}$ & 0.0039 & 0.0040 \\
\hline $\operatorname{Pin}^{7}$ & -0.0023 & -0.0027 \\
\hline
\end{tabular}

The same approach can be taken for the fitted curve after linearization shown in figure 19. The results are presented in the following table shown in Table V.

TABLE VI: power coefficient for $1^{\text {st }}$ and $3^{\text {rd }}$ order frequencies after linearization

\begin{tabular}{|l|l|l|}
\hline $\begin{array}{l}\text { Input power } \\
\text { order }\end{array}$ & $\begin{array}{l}\text { Coefficients for } \mathbf{1}^{\text {st }} \\
\text { order frequency } \\
(\mathbf{d B m})\end{array}$ & $\begin{array}{l}\text { Coefficients for } \mathbf{3}^{\text {rd }} \\
\text { order frequency } \\
(\mathbf{d B m})\end{array}$ \\
\hline $\mathrm{Pin}^{0}$ & 14.6385 & -45.8482 \\
\hline Pin & 2.0064 & 2.4239 \\
\hline Pin $^{2}$ & 0.7700 & 0.7937 \\
\hline Pin $^{3}$ & -0.6173 & -0.7349 \\
\hline $\operatorname{Pin}^{4}$ & -0.0930 & -0.0853 \\
\hline $\operatorname{Pin}^{5}$ & 0.0562 & 0.0652 \\
\hline $\operatorname{Pin}^{6}$ & 0.0042 & 0.0033 \\
\hline
\end{tabular}

It is observed by careful speculation, that the power order of table IV before linearization is up to the order of 7 . On the other hand, the order of power coefficient after linearization found in table $\mathrm{V}$ is up to the order of 6 . Moreover, the power coefficients seem less in table V than in table IV. Hence, this provides good evidence that linearity has improved by applying the negative impedance method.

According to table $\mathrm{V}$ and $\mathrm{VI}$, the equation for both $1^{\text {st }}$ and $3^{\text {rd }}$ order frequencies would be,

Before linearization,

For $1^{\text {st }}$ order frequencies

Pout $=14.66+2.09$ in $^{2}+0.75$ Pin $^{2}-0.64$ in $^{9}-0.09$ Pin $^{4}+$

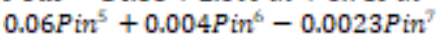

For $3^{\text {rd }}$ order frequencies,

Pout $=-45.95+2.52$ Pin $^{2}+0.88$ Pin $^{2}-0.76$ Pin $^{9}-0.1$ Pin $^{4}+$

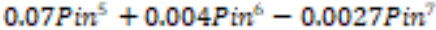




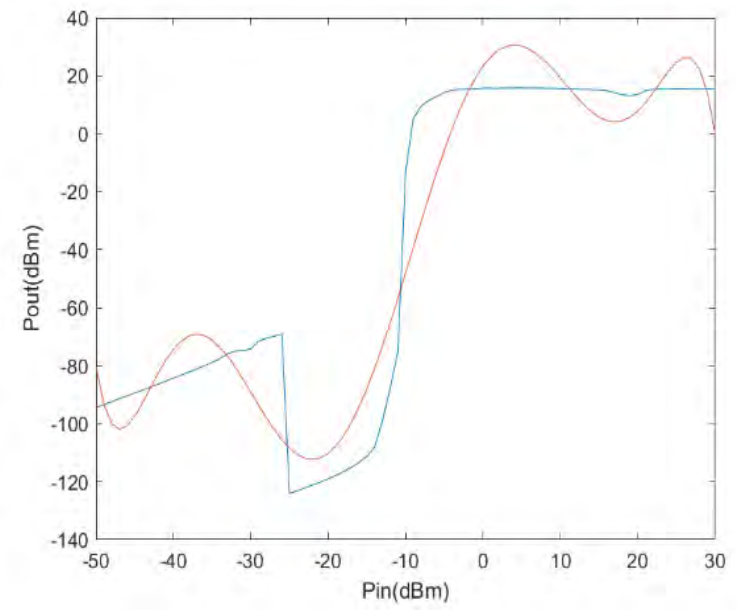

(a)

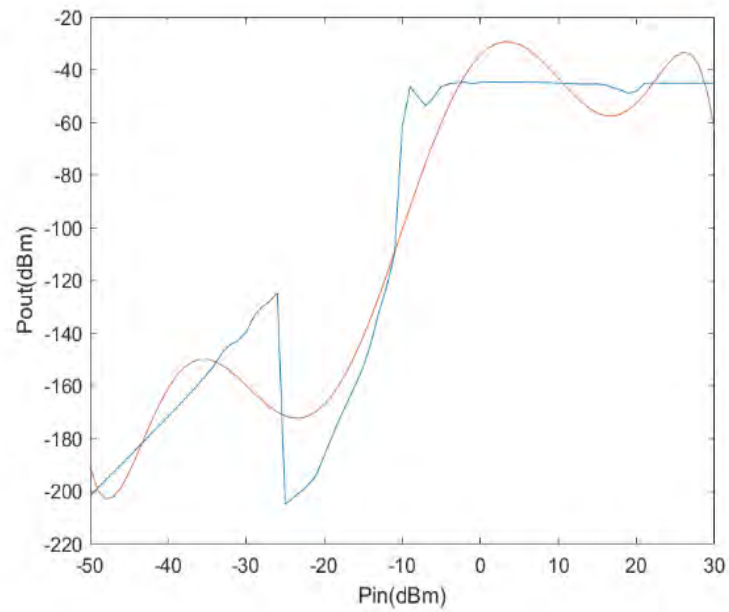

(b)

Fig. 18. original (blue) and fitted curve (orange) of (a) $1^{\text {st }}$ order frequency (b) $3^{\text {rd }}$ order frequency before linearization

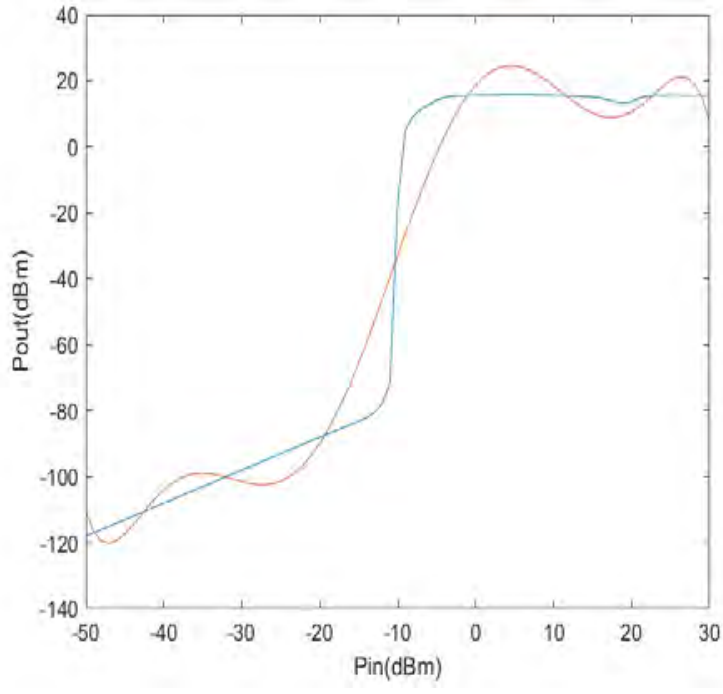

(a)

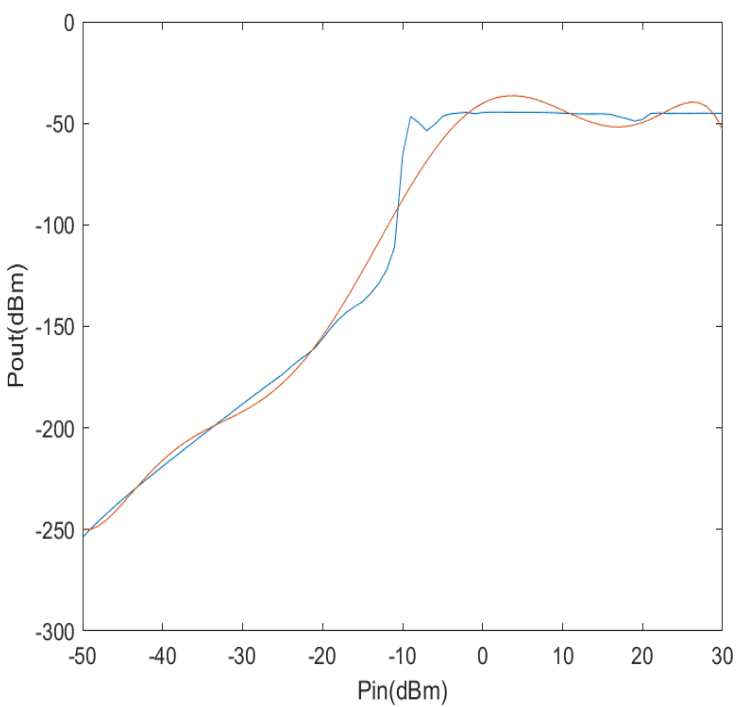

(b)

Fig. 19. original (blue) and fitted curve (orange) of (a) $1^{\text {st }}$ order frequency (b) $3^{\text {rd }}$ order frequency after linearization

After linearization,

For $1^{\text {st }}$ order frequencies

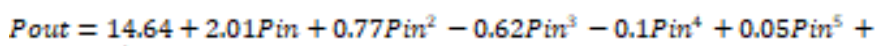
0.004 Pin $^{5}$

For $3^{\text {rd }}$ order frequencies,

Pout $=-45.84+2.42$ in $^{2}+0.8$ Pin $^{2}-0.73 P^{9}$ in $^{2}-0.08$ inn $^{4}+$ $0.065 P_{\text {in }^{5}}+0.003 P_{\text {in }}{ }^{6}$

\section{FUTURE SCOPE}

The goal of this work is to simulate and analyze the behavior of class $\mathrm{E}$ power amplifier with a linearization technique known as the negative impedance method. As this is a proof of concept, how the negative impedance is implemented in terms of circuit design is not presented in this work. There are several scopes for improvement in this work that can be done in the future. First and foremost, the device that is used is a 280nm CMOS process based on BSIM3v3 model. The design can provide much more power if more standard power MOSFET were used, typically LDMOS or more advanced processes like GaN HEMT. On the other hand, some designrelated improvements can also be done. Firstly, the current source that is used is an ideal one. In real life, it can be implemented with a Wilson current mirror along with a bandgap reference circuit [18]. Another improvement can be done by a power management block known as multilevel 
envelope tracking which can adjust the power supply according to necessity hence improving efficiency [19]. In order to get more robust and confident results, a physical custom layout of this work and post-layout simulation across different process corners, temperature, and supply can be done.

\section{CONCLUSION}

The motivation of this work was to apply a simple design to linearize a highly nonlinear switch-mode power amplifier, class E amplifier. This work provides a proof of concept of linearizing a class $\mathrm{E}$ amplifier with a negative impedance method. As previously discussed, the class E amplifier is a switch-mode power amplifier where the active device is operated as a switch. On the other hand, the negative method was originally made for a differential amplifier which provides an anti-distortion current at the input of a feedback differential amplifier. According to the results that are shown in previous sections, the linearity parameter IIP3 should remarkable improvement keeping all other performance parameters such as output power, power gain, and PAE. This work also provides a mathematical model for the designed amplifier which also provides evidence on linearity improvement. Hence, it can be said that the negative impedance method can be a good candidate for the linearization of class $\mathrm{E}$ amplifiers.

\section{REFERENCES}

[1] N. O. Sokal and A. D. Sokal, "Class E-A new class of high-efficiency tuned single-ended switching power amplifiers," in IEEE Journal of SolidState Circuits, vol. 10, no. 3, pp. 168-176, June 1975, doi: 10.1109/JSSC.1975.1050582.

[2] M. M. Hella, RF cmos power amplifiers: Theory, design and implementation. Dordrecht, Netherlands: Kluwer Academic, 2001.

[3] R. Kubowicz, "Class-E Power Amplifier," Collectionscanada.gc.ca. [Online]. Available: https://www.collectionscanada.gc.ca/obj/s4/f2/dsk1/tape4/PQDD_0017/MQ53 437.pdf. [Accessed: 28-Aug-2021].

[4] A. Mediano, P. Molina-Gaudo and C. Bernal, "Design of Class E Amplifier With Nonlinear and Linear Shunt Capacitances for Any Duty Cycle," in IEEE Transactions on Microwave Theory and Techniques, vol. 55, no. 3, pp. 484-492, March 2007, doi: 10.1109/TMTT.2006.890512.

[5] M. S. Sikder and M. T. Ali, "Performance analysis of High Frequency Class E Feedback amplifier with Schmitt Trigger driver," 2021 2nd International Conference on Robotics, Electrical and Signal Processing Techniques (ICREST), DHAKA, Bangladesh, 2021, pp. 451-455, doi: 10.1109/ICREST51555.2021.9331037.

[6] T.J. Bennett and Clements, R.F., 1974. "Feedforward an alternative approach to amplifier linearization." 1974 Radio and Electronic Engineer, 44(5), pp.257-262.

[7] T. Rahkonen and T. Kankaala, "An analog predistortion integrated circuit for linearizing power amplifiers," 1998 Midwest Symposium on Circuits and Systems (Cat. No. 98CB36268), Notre Dame, IN, USA, 1998, pp. 480-483, doi: 10.1109/MWSCAS.1998.759535.

[8]Chi-Tsan Chen, Chien-Jung Li, Tzyy-Sheng Horng, Je-Kuan Jau and Jian$\mathrm{Yu} \mathrm{Li}$, "Design and linearization of Class-E power amplifier for non-constant envelope modulation," 2008 IEEE Radio Frequency Integrated Circuits Symposium, Atlanta, GA, 2008, pp. 145-148, doi: 10.1109/RFIC.2008.4561405.

[9] P. Sampath, K. Gunavathi, "Class-E power amplifier and its linearization using analog predistortion. ", 2012

[10] M. T. Ali, R. Wu, P. Callaghan, and P. Rapajic, "Highly linear RF amplifier design: theoretical analysis and experimental study," Int. J. Electron., vol. 101, no. 1, pp. 98-112, 2014.

[11] M. Tanseer Ali, R. Wu, L. Mao, P. Callaghan, and P. Rapajic, "High frequency CMOS amplifier with improved linearity," IET Circuits Devices Syst., vol. 8, no. 6, pp. 450-458, 2014.
[12] R. Wu and M. T. Ali, "Stability analysis and stabilisation of an amplifier with non-linearity compensation," Int. J. Electron. Lett., vol. 6, no. 1, pp. 114126, 2018.

[13] "Cadence | Computational Software for Intelligent System Design ${ }^{\mathrm{TM}}$ ", Cadence.com, 2020. [Online]. Available:

https://www.cadence.com/en_US/home.html. [Accessed: 08- Dec- 2020]

[14] "The BSIM3 Model", Literature.cdn.keysight.com, 2020. [Online].

Available:

http://literature.cdn.keysight.com/litweb/pdf/iccap2008addon1/icmdl/icm d1052.html. [Accessed: 15- Oct- 2020]

[15] C. Zhang, A. Srivastava and P. K. Ajmera, "Low voltage CMOS Schmitt trigger circuits," in Electronics Letters, vol. 39, no. 24, pp. 1696-1698, 27 Nov. 2003, doi: 10.1049/el:20031131.

[16] R. Wu, F. J. Lidgey and K. Hayatleh, "Design of amplifiers with high gain accuracy and high linearity," 2007 50th Midwest Symposium on Circuits and Systems, Montreal, Que., 2007, pp. 269-272, doi: 10.1109/MWSCAS.2007.4488586.

[16] Microwaves101.com. 2021. Microwaves101 | Why Fifty Ohms?. [online] Available at: <https://www.microwaves101.com/encyclopedias/why-fiftyohms $>$ [Accessed 30 January 2021].

[17]"L-Matching", Analog/RF IntgCkts, 2020. [Online]. Available: https://analog.intgckts.com/impedance-matching/l-matching/. [Accessed: 13Oct- 2020]

[18] Dong-Ok Han, Jeong-Hoon Kim and Nam-Heung Kim, "Design of bandgap reference and current reference generator with low supply voltage," 2008 9th International Conference on Solid-State and Integrated-Circuit Technology, Beijing, China, 2008, pp. 1733-1736, doi: 10.1109/ICSICT.2008.4734888.

[19] N. E. Iversen, V. Lazarevic, M. Vasic, A. Knott, M. A. E. Andersen and J. A. Cobos, "Multilevel tracking power supply for switch-mode audio power amplifiers," 2018 IEEE Applied Power Electronics Conference and Exposition (APEC), San Antonio, TX, USA, 2018, pp. 406-411, doi: 10.1109/APEC.2018.8341043.

[20] Hongtao Xu, S. Gao, S. Heikman, S. I. Long, U. K. Mishra and R. A. York, "A high-efficiency class-E GaN HEMT power amplifier at $1.9 \mathrm{GHz}$," in IEEE Microwave and Wireless Components Letters, vol. 16, no. 1, pp. 22-24, Jan. 2006, doi: 10.1109/LMWC.2005.861355.

[21] M. P. van der Heijden, M. Acar and J. S. Vromans, "A compact 12-watt high-efficiency 2.1-2.7 GHz class-E GaN HEMT power amplifier for base stations," 2009 IEEE MTT-S International Microwave Symposium Digest, Boston, MA, 2009, pp. 657-660, doi: 10.1109/MWSYM.2009.5165782.

[22] K. Chen and D. Peroulis, "Design of Highly Efficient Broadband Class-E Power Amplifier Using Synthesized Low-Pass Matching Networks," in IEEE Transactions on Microwave Theory and Techniques, vol. 59, no. 12, pp. 3162 3173, Dec. 2011, doi: 10.1109/TMTT.2011.2169080.

[23] F. Tamjid, A. Ghahremani, M. Richardson and A. E. Fathy, "A novel approach to the design of a broadband high efficiency Class-E power amplifier with over $87 \%$ bandwidth," 2017 IEEE Topical Conference on RF/Microwave Power Amplifiers for Radio and Wireless Applications (PAWR), Phoenix, AZ, 2017, pp. 25-28, doi: 10.1109/PAWR.2017.7875564.

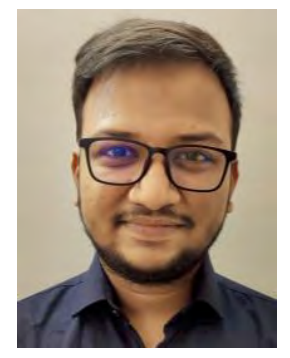

MD. Shoaib Sikder was born in Dhaka, Bangladesh on $21^{\text {st }}$ March 2021. He graduated with $\mathrm{BSc}$ in $\mathrm{EEE}$ from American International UniversityBangladesh, in 2020 with the prestigious Summa Cum Laude award, and enrolled in MSc in EEE program in the same year. He has completed his Master's Thesis on $5^{\text {th }}$ June 2021 titled "Linearization of High frequency Class E Feedback Amplifier using Negative Impedance Method" which is published in AJSE. Moreover, another paper titled "Performance analysis of High Frequency Class E Feedback amplifier with Schmitt Trigger driver" was published in International Conference on Robotics, Electrical and Signal Processing Techniques (ICREST) in 2021. He is currently working for Neural Semiconductor Limited with Analog Circuit Design team as an Associate Engineer. So far 
he has experience on ADCs, clocking circuits, amplifiers, and power conversion circuits as well.

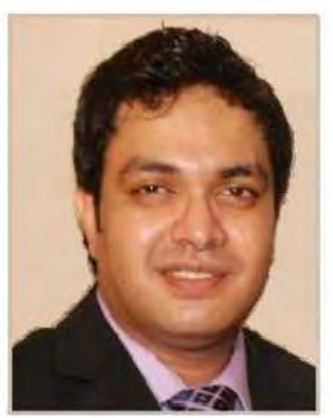

M Tanseer Ali has completed his B.Sc in Telecom and Electronics Engineering degree from North South University, Bangladesh in 2007 and then completed his M.Sc. in Communication Engineering from The Robert Gordon University, Aberdeen, UK in 2008. $\mathrm{He}$ received full-funded $\mathrm{PhD}$ Scholarship in 2009 and completed his $\mathrm{PhD}$ degree with Distinction from University of Greenwich, London, UK in 2013. He joined American International University - Bangladesh (AIUB) in 2013 and currently working as Associate Professor at the EEE Department, Faculty of Engineering. His primary research areas are CMOS circuit and Systems, Analogue and Mixed Signal Circuits, Microwave circuit and Systems, Nanoelectronics, IoT Systems, Automation and Robotics, Outcome based Engineering Education, etc. 